International Journal of Agriculture, Environment and Bioresearch

Vol. 5, No. 04; 2020

ISSN: $2456-8643$

\title{
POVERTY AMONG THE RURAL HOUSEHOLDS IN NIGERIA: A REVIEW OF WORLD MEASUREMENT METHODOLOGY
}

\author{
Bigwa Suben, Akinyemi Mudashiru, Ekpa Daniel and Gunu Umoru Ibrahim \\ Department of Agricultural Economics, Federal University Dutsin-Ma, Katsina State, Nigeria \\ Corresponding Author: makinyemi@ fudutsinma.edu.ng Tel: +2348150606588
}

https://doi.org/10.35410/IJAEB.2020.5524

\begin{abstract}
Poverty has become an all-inclusive threat to existence of humanity, Government at all levels has given thoughtful attention to reduce poverty in sub-Saharan Africa. This malady has reduced the value of humanity to impishness and endanger the human instinctiveness and potentials. The unending trap created by poverty is gradually consuming poor individual households thereby lessen their productivity, impose ultimate trap to economic development, siphoning and continuously draining the viable human resources to developed world in search for greener pasture. Extreme poverty if not checked and measured accurately may lead to loss of life. Twothirds of the world population currently live on poverty line of less than $\$ 2.00$ per day. This paper therefore seeks to review the methodology used in analysing poverty. The data used for the study is mainly from secondary source such as journals, statistical data base, and other documents, the study found out that unreliable data used by other methods such as Income based Approach and FGT method embroidered and blow up the research upshot, hence render the result invalid for policy analysis. However, the Individual Deprivation approach presents a down to the earth method and stand out to be more suitable poverty measurement. The Individual Deprivation Method provides a far deeper insights and nuance than income-based measures of poverty and moves well beyond the comparatively limited dimensions included in other multidimensional measures. The study concludes that the individual deprivation method offers an accurate technique to measure poverty and hence offer a foundation through which policy can be articulated. The study suggests that an exhaustive data base must be developed for research purpose and this will proffer solution to cankerworm of poverty in Nigeria. In this regards, government through the relevant institutions can give a helping hand to researcher to come up with a more reliable poverty measurement in developing countries.
\end{abstract}

Keywords: Poverty, Measurement, Methodology, world.

\section{INTRODUCTION}

Poverty has continually been a threat to human survival anywhere it seems to exist in the world. Poverty has become an unending trap, gradually engulfing the entire family ultimately and continuously, extreme poverty may lead to death (Moshin Khan, 2019). The alleviation and eradication of poverty has remained a critical issue among countries of the world during the last decade, and has also become the central goal and the top priority of the international 
development agenda (United Nation, 2015). Veritably, "Ending poverty in all its forms everywhere at any time" was framed as the first among the 17 Sustainable Development Goals (SDGs) which was adopted by the United Nation General Assembly on $25^{\text {th }}$ September 2015 (United Nation [UN], 2015).

"Poverty in most developing countries is largely a rural phenomenon" (Calyd T. Cerio, Filma C. Calalo, Sherry B. Marasigan and Josefina T. Dizon, 2019) The poor in rural areas and communities depend solely on resources that are common and they are primarily engage in subsistence agricultural farming activities such as fishing, mining, forestry, and other related small-scale industries and services (Calyd T. Cerio et al., 2019,Kapur, 2019; Khan, 2001; Ogutu and Qaim, 2019). They are often in need of productive assets needed to maximize their income and are constrained with the access to land, labour, inputs, irrigation and financial services (Food and Agriculture Organization, 2019)

In the last two decades poverty in Africa has become a subject of national concern. Nigeria which has been claimed to be the giant of Africa has in doubt suffered from the high growth rate of poverty among its citizens, this has also reflects the poor management and performance of the economies of the various States in Nigeria. There are many over-crowded settlements in major urban centres in Nigeria today such as Ajegunle, Oshodi, Ketu, Lagos Island and Agege - (all in Lagos). Ibadan, Kano, Onitsha, Benin etc. The rural areas of most Nigerian States are also hit with absence of basic social infrastructures such as light, water, health facilities and good roads. One wonders whether the people in these neglected areas did not take part in electing the ruling government functionaries.

Poverty has become more pervasive and a rising problem in countries worldwide mostly in developing nations of the world for example a country like Nigeria has currently slipped from being a buoyant and up-coming economy to rank number one with high rate of poverty (Yomi Kazeem, 2018). According to the new report by the World Poverty Clock, it showed Nigeria to have overtaken India as the country with the most extreme poor people in the world with over 86.9 million of its population living in extreme poverty (WPC, 2018). India has a population that is seven times larger than the Nigeria's population.

Despite the fact that poverty associated with some similarities both locally and internationally there existed a differing measure of yardstick. Internationally the combinations of major African nations are rated as most devastated followed by some parts of Asia and North American countries (Auwal, 2012).

Poverty is also recognized to be multifaceted (Alkire and Foster, 2007). Series of disagreement have been on-going among scholars on how many faces has poverty, however, among poverty scholars exists on what methodology to use in multidimensional poverty measurement. Methods such as the factor analysis, multiple correspondence analysis, and Principal Component Analysis (PCA) have evolved (Fransman and Yu, 2018) but the Alkire and Foster's (2011) Multidimensional Poverty Index (MPI) has gained general acceptance among scholars. According to Multidimensional Poverty Index assessment in 103 countries across the globe, a total of 1.45 billion individuals are multidimensional poor (Oxford Poverty and Human Development Initiative, 2017). This estimate is far higher than the reported more than 800 
million uni-dimensionally poor of the UN. Poverty, however, in the case of the United Nations data in 2015, made use of monetary measure of poverty which discriminates other dimensions of wellbeing. Even so, there is a broad consensus among scholars and institutions that acknowledge the limitation of monetary poverty measure (Chen, Leu, and Wang, 2019; Espinoza-Delgado and Klasen, 2019; Page and Pande, 2018). Although the monetary measure is a strong predictor of individual's wellbeing (Alkire, Kanagaratnam, and Suppa, 2018; Waggle, 2005) and provides beneficial information (Calderon and Kovacevic, 2015), it does not capture the holistic view such as the basic needs and the capability of the people as a basis for poverty identification (Chakra arty and Lugo, 2016; Sen, 2001).

\section{CONCEPTUAL FRAMEWORK}

Poverty has been widely defined by various scholars based on their understanding of the concept. Among many of such scholars, poverty according to Ewetan (2005) has been defined as a situation of low income or low consumption. It is said to exist when one or more persons fall short of a level of economic welfare deemed to constitute a reasonable minimum either in some absolute sense or by the standard of a specific society (Lypton and Ravallion, 1995) as cited in Adeyemo and Alayande, 2001. Poverty can also be said to be a situation where individuals are short or are in absence of physical necessities, assets and income for survival.

The United Nations defines poverty as; A denial of choices and opportunities, a violation of human dignity. It means lack of basic capacity to participate effectively in society. It means not having enough to feed or cloth a family, not having a school or clinic to go to, not having the land on which to grow one's food or a job to earn one's living, not having access to credit. It means insecurity, powerlessness, and exclusion of individuals, households and communities. It means susceptibility to violence, and it often implies living in marginal or fragile environments, without access to clean water or sanitation (United Nations, 2011).

It must be noted that the poor in most instances are unable to have access to basic necessities of life such as food, clothing, and decent shelter, unable to meet social and economic obligations, they lack skill, gainful employment, have inadequate possession of economic assets and sometimes lack of self-esteem (Kehinde Oladele Joseph, 2010)

On the nature of poverty, Ewetan (2005) emphasized that poverty may be chronic / structured or conjectural / transient. Structural or chronic poverty is long-term or persistent. Its causes are more permanent and depend on a number of factors such as limited productive resources, lack of skill for gainful employment, location disadvantage or endemic socio-political and cultural factors. The definition for poverty can be classified under the following:

Human Poverty: This is the lack of essential capabilities such as being literate or adequately nourished.

Income Poverty: The lack of minimum adequate income for expenditure and maintain healthy living conditions 
Extreme Poverty: Indigence or destination usually specified as the inability to satisfy minimum food needs.

Overall Poverty: This is the inability of an individual to satisfy essential non-food as well as food needs.

Relative Poverty: This is also called secondary poverty. It occurs as households overtime fall short of the resource to maintain their living standard. Relative poverty refers to a state in which an individual or households lack resources in comparison to members of another society because definitions of poverty in one place is not the same as in another environment, for example definition of poverty in Dutsinma is not the same as in Lagos or Abuja. That is why, poverty line is significantly higher in developed countries then the developing countries. Relative poverty fluctuates with income, expenditure and economic growth. The poverty line from this approach is of the mean income or expenditure. (Awoyemi et al, 2011). Relative poverty changes across countries or overtime.

Absolute Poverty: This is also known as primary poverty. It is a situation where households cannot meet the basic physiological survival needs. It is defined by a fixed standard. In this case an individual or households lacks resources necessary for subsistence. The household lacks income and access to social services such as electricity, water, health care and education. The poverty line from this approach has a fixed value.( Suleiman 2005).

Poverty Line: It is that income level below which a minimum nutritionally adequate diet plus essential non-food requirements are unaffordable. It is a measure that separates the poor from the non-poor according to World Bank individual living below \$2 are considered to be poor.

Human Development Index (HDI): This measures the average achievement of a country in basic human capabilities whether they live a long and healthy life, educated and knowledgeable and enjoy a decent standard of living. The three key components of HDI are standard of living, knowledge and longevity. The attractiveness of the HDI, based on these three quantifiable componentsis that it is simple, complex and objective rather than subjective.

Integrated Poverty Index (IPI): IPI combines the population below the poverty line with the income gap ratio (the percentage income gap between the country and the country with maximum GNP per capital among countries under study), the distribution of income among the poor and the annual rate of growth of the GNP per capita.Basic Need Index (BNI): BNI uses education and health data to indicate social development.

Gender Development Index (GDI): The GDI measures the magnitude of the disparity. Firstly, by expressing each of the three components of the HDI in terms of the female value as a percentage of the male value and secondly, by multiplying the overall HDI by the simple average female-male ratio to obtain the gender-disparity adjusted HDI.

Vicious Circle of Poverty: It is conceived as a vicious circle of compounding circumstances that leave the poor with few, if any, choices. Individuals constrained within this circle experience little improvement from year. The common feature of poor people whether male or female or 
whether found in developing or developed countries is that they are constrained within the vicious circle of poverty.

\section{Overview of World Poverty}

Most people in the world live in poverty. Two-thirds of the world population live on less than \$int. 10 per day. And every tenth person lives on less than \$-int. 1.90 per day (Max Roser and Esteban Ortiz-Ospina, 2019).Global poverty is one of the very worst problems that the world faces today. The poorest in the world are often hungry, have much less access to education, regularly have no light at night, and suffer from much poorer health. To make progress against poverty is therefore one of the most urgent global goals.

Over the course of the last generation more than a billion people left the most destitute living conditions behind. The world economy is growing. In less than a generation the value of the yearly global economic production has doubled (World Bank Data, 2017).Increasing productivity around the world meant that many left the worst poverty behind. More than a third of the world population now live on more than 10 dollars per day. Just a decade ago, it was only a quarter. In absolute numbers this meant the number of people who live on more than 10 dollars per day increased by 900 million in just the last 10 years (World Bank, 2015).

In fact, the big success over the last generation was that the world made rapid progress against the very worst poverty. The number of people in extreme poverty has fallen from nearly 1.9 billion in 1990 to about 650 million in 2018 (World Bank, 2018). This was possible as economic growth reached more and more parts of the world. In Ethiopia, India, Indonesia, Malaysia, Ghana, and China more than half the population lived in extreme poverty a generation ago. But after two decades of growth the share in extreme poverty more than halved in all these countries (Max Roser and Esteban Ortiz-Ospina, 2019).

Poverty was not concentrated in Africa until recently. In 1990 more since then those economies have grown faster than many of the richest countries in the world and did much to a reduction of global inequality. The concentration of the world's poorest shifted from East Asia in the 1990s to South Asia in the following decade. Now it has shifted to Sub-Saharan Africa. The projections suggest the geographic concentration of extreme poverty is likely to continue. According to the World Bank forecasts $87 \%$ of the world's poorest are expected to live in Sub-Saharan Africa in 2030 if economic growth follows the trajectory over the recent past. Many of the world's poorest today live in countries that had very low economic growth in the past(Martin Ravallion, 2016).Consider the case of Madagascar: In the last 20 years GDP per capita has not grown; and the number in extreme poverty increased almost one-for-one with total population.

A recent reports and statistics by The World Poverty Clock shows Nigeria rank first among ten African countries with people living in extreme poverty. 
Table showing countries with population living in extreme poverty

\begin{tabular}{|l|l|l|}
\hline S/N & Countries & People living in Extreme poverty (Millions) \\
\hline 1 & Nigeria & 86.9 \\
\hline 2 & Democratic Republic of Congo & 60.9 \\
\hline 3 & Ethiopia & 23.9 \\
\hline 4 & Tanzania & 19.9 \\
\hline 5 & Mozambique & 17.8 \\
\hline 6 & Kenya & 14.7 \\
\hline 7 & Uganda & 14.2 \\
\hline 8 & South Africa & 13.8 \\
\hline 9 & South Sudan & 11.4 \\
\hline 10 & Zambia & 9.5 \\
\hline
\end{tabular}

\section{Source: World Poverty Clock Data 2018}

Crucially, of those countries in top ten, only Ethiopia is on track to meet the United Nations' SDG of ending extreme poverty by 2030. Outside the top ten, only Ghana and Mauritania are also on track with the SDG target. Indeed, of the 15 countries across the world where extreme poverty is rising per World Poverty Clock data, 13 are currently in Africa.

As a consequence, the mission to end extreme poverty globally is already at risk. By July 2018, 83 million people would have been lifted out of extreme poverty since January 2016 but the number is 37 million people fewer than the required to meet the 2030 target this can be seen in the table below.

Country Percentage of population in extreme SDG1 status poverty 
Vol. 5, No. 04; 2020

ISSN: $2456-8643$

\begin{tabular}{|l|l|l|}
\hline Nigeria & 46.7 & Poverty rising \\
\hline $\begin{array}{l}\text { Democratic Republic of } \\
\text { Congo }\end{array}$ & 77 & Poverty rising \\
\hline Ethiopia & 23.4 & On track \\
\hline Tanzania & 35 & Off track \\
\hline Mozambique & 61.8 & Off track \\
\hline Kenya & 30 & Off track \\
\hline Uganda & 34.2 & Off track \\
\hline South Africa & 24.6 & Off track \\
\hline South Sudan & 93 & $\begin{array}{l}\text { Poverty } \\
\text { Rising }\end{array}$ \\
\hline Zambia & 57.2 & Poverty \\
\hline
\end{tabular}

\section{Source: World Poverty Clock Data 2018}

\section{Causes of Poverty}

More than half of the world population toady live in extreme poverty; taking this scenario, an individual is obligated to feed his family, travel through and from work, pay the school fees of his children, payment of other bills such as water, electricity, cable and so on, but is with just $\$ 1.90$ in his pocket, this is an impossible quest for survival of any individual But on an average, approximately 800 million people in the world live in this reality. $11 \%$ of the world's population today is living in extreme poverty, which is defined as surviving on only $\$ 1.90$ a day (World Bank, 2016). While many have argue that there's no way to truly get rid of poverty since poverty in itself is multidimensional and multi-faced, however, extreme poverty can be eradicated. Unfortunately, there is no "magic bullet" solution, but to solve the problem of poverty one must understand most of it causes. According to Concern World Wide US 2019 listed the following as the top cause of poverty worldwide. 
Inadequate Access to Clean Water and Nutritious Food: Currently, more than 2 billion people don't have access to clean water at home, while over 800 million suffer from hunger. You might think that poverty causes hunger and prevents people from accessing clean water (and you would be right!), but hunger and water insecurity are also big reasons why people struggle to escape extreme poverty. If a person doesn't get enough food, they simply don't have the strength and energy needed to work, while lack of access to food and clean water can also lead to preventable illnesses like diarrhoea. And when people assets, and can knock a family from poverty into extreme poverty

No Access to means of Livelihoods: This might seem a bit like a "no brainer." Without a job or a way to make money, people will face poverty. But it's easy to assume that if someone wants a job, they could have one. That just isn't true, particularly in developing and rural parts of the world. Dwindling access to productive land (often due to conflict, overpopulation, or climate change), and overexploitation of resources like fish or minerals is putting increasing pressure on many traditional livelihoods.

Conflict: Conflict can cause poverty in several ways. Large scale, protracted violence that we see in places like Syria can grind society to a halt, destroy infrastructure, and cause people to flee, forcing families to sell or leave behind all their assets. In Syria, around $70 \%$ of the entire population now lives below the poverty line - this in a country where extreme poverty was once very rare. Women often bear the brunt of conflict: during periods of violence, female-headed households become very common. And because women often have difficulty getting well-paying work and are typically excluded from community decision-making, their families are particularly vulnerable.

Poor Education: Not every person without an education is living in extreme poverty. But most of the extremely poor don't have an education. And why is that? There's a lot of barriers stopping children from going to school. Many families can't afford to send their children to school and need them to work. Many people don't see a benefit in educating girls. Education is often referred to as the great equalizer, and that's because education can open the door to jobs and other resources and skills that a family needs to not just survive, but thrive. UNESCO estimates that 171 million people could be lifted out of extreme poverty if they left school with basic reading skills. And, with even more education, world poverty could be cut in half.

Climate Change: You might be stunned to learn that the World Bank estimates that climate change has the power to push more than 100 million people into poverty over the next ten years. As it is, climate events like drought, flooding, and severe storms disproportionately impact communities already living in poverty. Why? Because many of the world's poorest populations rely on farming or hunting and gathering to eat and earn a living. They often have only just enough food and assets to last through the next season, and not enough reserves to fall back on in the event of a poor harvest. So when natural disasters (including the widespread droughts caused by El-Niño) leave millions of people without food, it pushes them further into extreme poverty.

Lack of Infrastructure: Imagine that you have to go to work or to the store, but there are no roads to get you there. Or heavy rains have flooded your route and made it impassable. What would you do then? A lack of infrastructure from roads, bridges, and wells to cables for light, 
cell phones, and internet can isolate communities living in rural areas. Living "off the grid" means the inability to go to school, work, or market to buy and sell goods. Traveling farther distances to access basic services not only takes time, it costs money, keeping families in poverty. Isolation limits opportunity, and without opportunity, many find it difficult, if not impossible, to escape extreme poverty.

Unstructured Social Welfare Programs: Many people living in the United States are familiar with social welfare programs that people can access if they need healthcare or food assistance. But not every government can provide this type of help to its citizens - and without that safety net, there's nothing to stop vulnerable families from backsliding further into extreme poverty if something goes wrong. Ineffective governments also contribute to several of the other causes of extreme poverty mentioned above, as they are unable to provide necessary infrastructure or ensure the safety and security of their citizens in the event of conflict.

Lack of Reserves: People living in poverty don't have the means to weather the storms of life. So when there is a drought, or conflict, or illness, there is little money saved or assets on hand to help. In Ethiopia for example, repeated cycles of drought have caused harvest after harvest to fail, causing a widespread hunger crisis. To cope, families will pull their children from school, and sell off everything they own to eat. That can help a family make it through one bad season, but not another. For communities constantly facing climate extremes or prolonged conflict, the repeated shocks can send a family reeling into extreme poverty and prevent them from ever recovering.

\section{Methodologies used in Poverty Measurement}

"Ever since the early 1900's, measurements of poverty have traditionally followed an economistic approach based on income and consumption levels. Over the last decades social scientists have criticised this approach and have produced an impressive amount of work presenting alternative definitions and ways of measuring poverty"(Sikandar Hasan, 2002).

\section{The Traditional Approach Poverty Index:}

This measure is based on headcount of poor individuals below the specified cut-off point, that is, the proportion of the population whose standard of living is less than the poverty line to the number of individuals or households. However, the headcount index does not indicate the depth of poverty, that is, how poor the individuals/households are, hence, the evolution of the poverty gap index. Poverty gap index is the ratio of the average extra consumption that would be required to bring all poor people or households up to the poverty line. The poverty gap is interpreted as measuring the depth of poverty.

\section{Income-based Poverty Measures}

The International Poverty Line, established by The World Bank, provides an example of incomebased measures of poverty. Here poverty is calculated according to the daily amount required by a person to meet his or her food requirements (typically 2,100 calories per person per day) and essential non-food needs. The amount of money required per person per day is then calculated 
according to costs in a particular country (known as purchasing power parity), and converted into a common currency (US dollars) for the purposes of comparison across countries (Ravallion et al., 2008).

Many countries have national income-based poverty lines. In some cases, such as India,poverty lines are different for rural and urban areas. Households are generally the unit of analysis, with a household determined as poor or not according to the amount of income divided across the number of members.

Income-based measures of poverty calculated in this way are particularly problematic from a gender perspective. They pay no heed to details of what happens to income once it enters households - that is, to access to and control over money and how it is spent, which means these measures fail to track different outcomes for individuals within the household (Chant 2005). Households are institutions distinguished not by relationships of harmony presided over by a benign household head, but by relations of conflict and co-operation rooted in gender and other dimensions of difference (Sen, 1990). In households, there are 'multiple actors, with varying (and often conflicting) preferences and interests, and differential abilities to pursue and realize those interests' (Agarwal, 1997). Gender, age, and position in the family are among the many dimensions of difference which shape reality and power for an individual. Differences in the bargaining power of household members, and gender norms, necessarily have implications for the intra-household distribution of resources. For example, hardship resulting from seasonal shortages or economic crisis falls disproportionately on women within poor households, as they reduce consumption, deplete their assets as a coping strategy, and take on heavier work burdens (Agarwal, 1990).

\section{Limitations}

The income-based measures of poverty are entirely unable to capture the full range of value of household labour. They ignore the economic worth of unpaid work: subsistence agriculture, family labour of women and children in production, and unpaid care work undertaken within the households and communities. This is critical to a gendered understanding of poverty, since unpaid work is overwhelmingly performed by women and children.

In addition to needing to reveal difference and inequality with the household, it is also important that any measure of poverty should reveal and provide insight into differences between households in different contexts. Sonalde Desai (1992) correctly reminds us that 'the conditions that affect cooperation and conflict in the relationship between family members vary across cultures and across socioeconomic contexts'. Poverty measures therefore need to focus on individuals, not households, in order to gain a nuanced understanding of what poverty actually means to individual women and men, boys and girls. They also need to move beyond income alone.

\section{Multi-dimensional Poverty Measures}

Multi-dimensional approaches to the conceptualisation and measurement of poverty have their theoretical origins in the capability approach pioneered by Amartya Sen (1984), and offer greater 
potential than income-based measures to be gender-sensitive. Martha Nussbaum (2001) has sought to illuminate the intersections between a capabilities approach and feminism. In practice, however, multi-dimensional approaches have yet to fulfil their promise of sensitivity to gender difference and inequality.

The Multi-dimensional Poverty Index (MPI), developed via the Oxford Poverty and Human Development Initiative at the University of Oxford, is described by its creators as 'an index of acute multidimensional poverty reflecting deprivations in very rudimentary services and core human functioning's' (Alkire and Santos, 2011).

Reflecting the increasing influence of multi-dimensional approaches to poverty measurement, the MPI was adopted by UNDP in 2010 and is used in several countries, often alongside incomebased measures. The MPI determines poverty not by income, but by deprivation in health, education, and standard of living, measured at household level using ten indicators. The MPI is described as revealing 'the combination of deprivations that batter a household at the same time' (Alkire and Santos, 2011).

\section{Limitations}

The revelation made by the MPI is important, but has a critical weakness in that it does not delve beneath household level to reveal the different experiences of individuals according to gender, age, and other important aspects of identity. While households collectively suffer from poverty, deprivation, and unequal access to services, not all members of a household suffer in the same way or to the same extent.

Conversely, several well-known measures of gender equality/inequality have little light to shed on the gendered experience of poverty and economic inequality. For reasons of space these will not be discussed here, but examples are the Gender-related Development Index (GDI) and the Gender Empowerment Measure (GEM), launched by UNDP in 1995.

\section{Foster Greer and Thorbecke (FGT) Poverty Measure}

The Foster Greer and Thorbecke measure of poverty sought to eliminate the short coming of Sen's measure of poverty his doubts about Sen's "rank weighting " approach and proposed an alternative "shortfall weighting" method that became the basis for the squared gap measure P2 featured in FGT paper. The FGT paper contributed to the literature on poverty in several ways:

(i) It introduced a new class of poverty measures that is understandable, theoretically sound, and applicable;

(ii) It helped justify the measures using new and practical axioms; and

(iii)It provided a concrete illustration of the new technology.

The FGT class is based on the normalized gap $g_{i}=(z-y i) / z$ of a poor person $i$, which is income shortfall expressed as a share of the poverty line.7 Viewing gia as the measure of individual poverty for a poor person, and 0 as the respective measure for non-poor persons, $\mathrm{P} \alpha$ is the average poverty in the given population. The case $\alpha=0$ yields a distribution of individual poverty levels in which each poor person has poverty level 1; the average across the entire 
population is simply the headcount ratio $\mathrm{P} 0$ or $\mathrm{H}$. The case $\alpha=1$ uses the normalized gap gi as a poor person's poverty level, thereby differentiating among the poor; the average becomes the poverty gap measure P1 or HI. The case $\alpha=2$ squares the normalized gap and thus weights the gaps by the gaps; this yields the squared gap measure P2. As $\alpha$ tends to infinity, the condition of the poorest poor is all that matters. The parameter $\alpha$ has an interpretation as an indicator of "poverty aversion" in that a person whose normalized gap is twice as large has $2^{\alpha}$ times the level of individual poverty.

Alternatively, $\alpha$ is the elasticity of individual poverty with respect to the normalized gap, so that a $1 \%$ increase in the gap of a poor person leads to an $\alpha \%$ increase in the individual's poverty level.8 The parametric class of measures gave analysts and policymakers an instrument to evaluate poverty under different magnifying glasses with varying sensitivity to distributional issues. The FGT paper also made ease poverty measurement by developing a parametric class of measures having desirable characteristics and a simple structure that policymakers could understand.

The General formula for FGT class of poverty is

$$
P_{\alpha}=\frac{1}{N} \sum_{i=1}^{q}\left(\frac{z-y_{i}}{z}\right)^{\alpha}
$$

Where

$\alpha=$ the FGT index and takes values 0,1 or 2

$\mathrm{n}=$ total number of households

$q=$ number of households below the poverty line

$\mathrm{Z}=$ poverty line

\section{Limitation.}

The FGT poverty measure is one renowned and know for it qualitative approach to the measurement of poverty which has improve works on quantifying poverty, however this measure of multidimensional poverty fail to capture the gender defences of poverty measurement since individuals in a given household face poverty on both gender basis also with the used of existing data which are most time not reliably available and true.

\section{Individual Deprivation Measure (IDM)}

The Individual Deprivation Measure seeks to overcome the gender insensitivity of existing measures of poverty, and in doing so reveals both gendered and other forms of inequality. The IDM captures an individual's status using two axes. Financial deprivation is plotted on the y axis, and 15 dimensions of poverty are plotted on the $\mathrm{x}$ axis. These are intended to capture the individual's experience of individual, multidimensional deprivation (Wisor et al., 2014). 
Financial deprivation is featured on a different axis rather than including it among the dimensions since it is clearly central to measuring poverty (indeed, during our research participants overwhelmingly identified income and ownership of assets as central to measuring poverty, deprivation, and inequality). Yet, including income or wealth in the dimensions may have a distorting effect on participants' response to questions relating to other dimensions. By plotting financial deprivation on one axis and multi-dimensional poverty on another, policymakers and practitioners are able to identify and track the relationship between the two forms of deprivation. This is an approach that is accepted and used in other multi-dimensional poverty measures.

Each dimension has one or more indicators, developed from research with participants with experience of living in poverty in different contexts, a review of the relevant literature and existing measures, and consultation with expert stakeholders. The indicators are a distillation of those raised in different contexts into a universal list to ensure the measure can be used in different contexts in the global South and potentially in the North. The IDM includes dimensions such as food/nutrition, water, shelter, and health care, which are shared by some existing measures of poverty or inequality. In some of these dimensions, however, the indicators are somewhat different from those used in existing poverty measures. For example, in relation to health, the IDM's indicators measure both health status, and access to health care. An additional question is asked of women who are pregnant or have been pregnant in the past three years, in order to measure access to maternal health care. The IDM also includes various dimensions that are rarely included in measures of poverty, inequality, or deprivation.

\section{Limitation}

One of the major limitation of this approach is to capture poverty rate among children in a given household, this approach is practically applicable to adult individually.

\section{LITERATURE REVIEW ON POVERTY MEASUREMENTS}

A review of the literature reveals various measure that have been used by researchers in countries worldwide to measure and provide various solution to poverty.

Amartya Sen, in his 1976 seminal paper "Poverty: An Ordinal Approach to Measurement," identified two steps that poverty measurement must address: (1) the identification of the poor among the population and (2) the aggregation of poverty data into an overall index. "Identification starts at the level of individual households or people while aggregation creates society-wide poverty measures" (Alkire, 2018).

Recent developments in literature on poverty measurement have highlighted serious limitations of single dimensional approaches to measure poverty. Santos and Ura (2008) and Alkire and Santos (2010) asserted that poverty is intrinsically multidimensional phenomenon and therefore needs to be measured through multidimensional approach, because of some fundamental flaws identified in exclusively focusing upon consumption or income data while analysing poverty. 
Vol. 5, No. 04; 2020

ISSN: $2456-8643$

Apablazay et al., (2010) emphasized that the insufficiency of an exclusive income approach to poverty measurement has led to consider and quantify poverty as deprivation in multiple dimensions of well-being.

Angulo (2016) argued that the Multidimensional Poverty Index (MPI) is more flexible when compared to other poverty measures. He highlighted that MPI can provide multidimensional poverty indicators for policy considerations.

Adetola and Olufemi (2012) used the multidimensional poverty approach to study the determinants of child poverty in rural Nigeria. Also, World Bank (2017) used the multidimensional approach to study poverty situation of Nigerians in terms of access to water supply, sanitation and hygiene.

Rogan (2016) showed that the incidence of multidimensional poverty is higher for femaleheaded households (9.4 percent) than male-headed households (6.8 percent). This indicates that female headed households are significantly more likely to be multi-dimensionally poor than male counterparts.

A spatial analysis of MPI in the Gauteng province of South Africa by Mushongera et al. (2017) found out that low income earning households, poor accessibility to infrastructures and unemployment (as a result of low concentration of economic activities in specific locations) increases the likelihood of a household to be multi-dimensionally poor.

Oni and Yusuf (2007) examined the determinants of expected poverty among rural households in Nigeria. The data for the study were analysed using three stage feasible generalized least squares (FGLS). The study found that farming households have lower mean per capita consumption compared with their non-farming households.

\section{DISCUSSION}

Empirical review of literature studies on poverty measurement reveals that majority of work done on poverty made use of the MPI and FGT poverty index to measure poverty rate. Poverty in its self has many dimension and this critical factors must not be neglected to understanding and having a concise and precise measure with understanding to cause, effect and possible recommendation to poverty measurements. Furthermore, the reviewed literature and existing measures of poverty and inequality used, are majorly based or relied on existing and often inadequate data sources. The measures of poverty relying on existing data is fathomable. But clearly, having data that are reasonably reliable and comparable is much more important if any measure is to be robust. Also there exist problems of reliability and of patchy data that exist in some of countries.

Moreover, and more importantly, much existing data are not adequate to measure the dimensions of poverty that matter most to people, and particularly to women. So long as researchers remain limited by existing data sources, then understanding poverty will continue to remain limited with limited responses. 
This shortcoming has made the IDM to be distinct from other measures. The IDM is distinct in three important ways. First, it is grounded in participatory research with people in poor communities in 18 sites across six countries. Unlike most mainstream measures of poverty or inequality, the IDM explicitly incorporates the priority issues identified by those living in poverty. Second, the IDM departs from the dominant measures of poverty in taking the individual, rather than the household, as the unit of analysis. This enables it to reveal the details of experiences of inequality within households. We can analyse how individuals in the same household experience the impact of financial deprivation differently, as well as the role of nonmonetary deprivation in the ways individual household members experience poverty. Crucially, this enables comparison of how a particular social category - for example, adolescent girls experience poverty in a particular community. Third, the IDM is not constrained by existing (and limited) data sources, which are often insensitive to gender-based inequality and do not reveal the dimensions of poverty that are important to poor people.

\section{CONCLUSION}

Poverty is a very serious problem bedevilling almost every nation in the world. However, the intensity and magnitude varies from one place to another. Globally, South-East Asia and subSaharan Africa has the largest proportion of their citizens trapped by poverty. The IDM is by no means the perfect tool. It does, however, demonstrate how we can do better in measuring poverty in ways that are sensitive to inequalities on the basis of gender, generation, and other individual characteristics. The IDM provides far deeper insights and nuance than income-based measures of poverty and moves well beyond the comparatively limited dimensions included in other multidimensional measures.

\section{RECOMMENDATION}

To eliminate the shortcoming of various approach and measurement to multidimensional poverty the Individual deprivation method stand out to be a potentially powerful tool in understanding the complexities of poverty and in contributing to policy responses. Therefore, exhaustive data base must be developed for research purpose and this will proffer solution to cankerworm of poverty in Nigeria. Furthermore using the Individual deprivation method it provides a way of taking gender seriously as an analytic category in the measurement of poverty, and revealing the depth and nature of poverty among women and men. Focusing on the individual, sensitive not only to gender, but also to other individual characteristics that may intensify poverty. It moves beyond income, and towards the dimensions of poverty that those with lived experience of poverty consider important. Government through the relevant institutions can give a helping hand to researcher to come up with a more reliable poverty measurement in developing countries.

\section{REFERENCE}

Adetola, A. and Olufemi, P. (2012). Determinants of child poverty in rural Nigeria: A multidimensional approach. Global Journal of Human Social Science Arts \& Humanities, 12(12), $39-54$ 
Adeyemo, A. and Alayande, T. (2001). "The Impact of Government Poverty Alleviation Programmes on Entrepreneurship Development in Nigeria." Development Policy Centre, Ibadan.

Alkire, S. and Foster J.E. (2011b). Understandings and misunderstandings of multidimensional poverty measurement. Journal of Economic Inequality. 9(2), 289-314.

Alkire, S. and Foster, J.E. (2011a). Counting and multidimensional poverty measurement. Journal of Public Economics, 95(7-8), 476-487.

Alkire, S., \& Foster, J. (2007). Counting and multidimensional poverty measurement (OPHI working paper). doi:10.1094/PDIS-91-4-0467B

Alkire, S., \& Foster, J. E. (2011). Counting and multidimensional poverty measurement. Journal of Public Economics, 95(7-8), 476-487. doi:10.1016/j.jpubeco.2010.11.006

Alkire, S., Kanagaratnam, U., \& Suppa, N. (2018). The global multidimensional poverty index (MPI): 2018 revision (OPHI MPI Methodological Notes 46). Oxford Poverty and Human Development Initiative, University of Oxford.

Alkire, Sabina, and Santos, María Emma (2011) 'Acute multidimensional poverty: a new index for developing countries', Proceedings of the German Development Economics Conference, no. 3. Berlin

Angulo, R. (2016). From multidimensional poverty measurement to multi-sector public policy for poverty reduction: lessons from the Colombian case. OPHI Working Paper 102, University of Oxford.

Apablazay, M., Pablo J., Ocampo J.P. and Yalonetzkyz G. (2010). Decomposing changes in multidimensional poverty in 10 countries. Oxford Poverty and Human Development Initiative, University of Oxford. 15pp.

Auwal, S., Northern Nigeria: surfacing poverty on untapped wealth. From https://www.gamji.com article. Retrieved on 27/01/2020.

Awoyemi, T. T; Falusi, A. O.; Idowu A, .O. and Omonona B. T. (2011). "Non-Farm Income Diversification and Poverty among Rural Farm Households in Southwest Nigeria" Journal of American Science. Vol. 8, (1), 77 - 82.

Chakravarty, S. R., \& Lugo, M. A. (2016). Multidimensional indicators of inequality and poverty. In M. Adler \& M. Fleurbaey (Eds.), The Oxford handbook of well-being and public policy (pp. 246-285). Oxford: Oxford University Press.

Chant, Sylvia (2005) 'Re-thinking the "Feminization of Poverty" in relation to aggregate gender indices', Journal of Human Development 7(2): 201-20 
Edoh, T (2003). "Poverty and the survival of Democracy in Nigeria". In Nigerian Journal of political and Administrative Studies. (Makurdi Aboki Publishers)" 1(1), 30 - 45

Edoumiekumo, S.G., Karimo T.M. and Tombofa S.S. (2014). Income poverty in Nigeria: Incidence, gap, severity and correlates. American Journal of Humanities and Social Sciences, 2(1), 1-9.

Espinoza-Delgado, J., \& Klasen, S. (2019). Gender and multidimensional poverty in Nicaragua: An individual based approach. World Development., 110, 466491.doi:10.1016/j.worlddev.2018.06.016

Food and Agriculture Organization. (2019). The role of agriculture and rural development in achieving SDG 1.1. Retrieved from https://www.un.org/development/desa/dspd/wpcontent/uploads/sites/22/2019/03/FAO-ending-extreme-rural-poverty-1.pdf

Kapur, R. (2019). Resource use and management of livelihood context in rural households in India. Acta Scientific Agriculture., 3(4), 150-160.

Khan, M. H. (2001, March). Rural poverty in developing countries: Implications for public policy. Retrieved from International Monetary Fund http://www.imf.org/external/pubs/ft/issues/issues26/

Lawrence, A., Neidhardt M., Aylward C., Biscaye P., Anderson L.C. and Reynolds T. (2016). Economic growth and poverty in Nigeria. Evans School Policy Analysis and Research (EPAR) Technical Report No.327.

Martin Ravallion (2016) - Are the world's poorest being left behind? In the Journal of Economic Growth. Retrieved from https://link.springer.com/article/10.1007/s10887-016-9126-7

Max Roser and Esteban Ortiz-Ospina (2020) - "Global Extreme Poverty". Published online at OurWorldInData.org. Retrieved from: 'https://ourworldindata.org/extreme-poverty' [Online Resource]

Moshin Khan (2019,Aug 27) Poverty | a threat to human security Retrieved on 20/01/2020 from https://medium.com/@MohsinSad123/poverty-a-threat-to-human-security-1336bd7ade7b

Mushongera D., Zikhali P., Ngwenya P. (2017) A multidimensional poverty index for Gauteng Province South Africa: Evidence from Quality of Life Survey Data, Social Indicators Research, 130 (1), 277-303.

Ogutu, S. O., \& Qaim, M. (2019). Commercialization of the small farm sector and multidimensional poverty. World Development. 114, 281-293. doi:10.1016/j.worlddev.2018.10.012

Ogwumike, F. (1997)., Basic Needs-oriented Approach to the measurement of poverty". Nigeria Journal of Economics and Social Studies. 33(2), 18-29. 
Olaniyan O. and Bankole, A. S. (2005) Human capital, capabilities and poverty in rural Nigeria. Research Report submitted to the African Economic Research Consortium.

Olaniyan, O. (2000). The role of household endowments in determining poverty in Nigeria. University of Ibadan, Nigeria

Oni O. A, Yusuf S. A. (2007) Expected Poverty Profile among Rural Households in Nigeria. African Journal of Economic Policy. 15(1), 139-162.

Oyinbo, O. and Olaleye, K.T. (2016). Farm households' livelihood diversification and poverty alleviation in Giwa Local Government Area of Kaduna State, Nigeria. The Journal of Sustainable Development. 15(1), 219-232.

Page, L., \& Pande, R. (2018). Ending global poverty: Why money isn't enough. Journal of Economic Perspectives, 32 (4), 173-200.

Rogan M. (2016) Gender and multidimensional poverty in South Africa: Applying the global multidimensional poverty index (MPI): Social Indicators Research, 126(3), 987-1006.

Santos, M.E. and Ura, K. (2008). Multidimensional poverty in Bhutan: Estimates and policy implications. Oxford Poverty and Human Development Initiative (OPHI). Oxford Department of International Development. Queen Elizabeth House, University of Oxford. OPHI Working Paper No.14. 25pp.

Sen, Amartya (1990) 'Gender and cooperative conflicts', in Irene Tinker (ed.) Persistent Inequalities: Women and World Development, New York: Oxford University Press, pp. 123-148. https://doi.org/10.1080/23311886.2019.1665397 from Taiwan. Social Indicators Research. doi:10.1007/ s11205-019-02118-8.

Sulaiman, J., Azman, A., and Abdelhak, S., (2013). "Vulnerability to Poverty among Paddy Farmers in Perlis, Malaysia" What Institutions Can Do? Background Paper for the Poverty Reduction in Asia: Drivers, Best Practices and Policy Initiatives. Sogang University, Seoul.

Ucha, C. (2010). Poverty in Nigeria: Some dimensions and contributing factors. Global Majority e-Journal. 1(1): $46-56$.

UN. (2015). Resolution adopted by the general assembly on 25 September 2015. United Nations General Assembly A/RES/70/1, Seventieth Session, Agenda items 15 and 116. Retrieved from http://www.un.org/ga/search/view_doc.asp?symbol=A/RES/70/1\&Lang=E.

Waggle, U. (2005). Multidimensional poverty measurement with economic well-being, capability, and social inclusion: A case from Kathmandu, Nepal. Journal of Human Development, 6(3), 301-328. 
International Journal of Agriculture, Environment and Bioresearch

Vol. 5, No. 04; 2020

ISSN: $2456-8643$

World Bank (2017). A Wake up Call: Nigeria Water Supply, Sanitation, and Hygiene Poverty Diagnostic. WASH Poverty Diagnostic. Washington DC; World Bank.

Yomi Kazeem (2018, June 25) A DIM OUTLOOK Nigeria has become the poverty capital of the world Retrieved on 20/01/2020 fromhttps://qz.com/africa/1313380/nigerias-has-thehighest-rate-of-extreme-poverty-globally/ 